\title{
Global aphasia as a predictor of mortality in the acute phase of a first stroke
}

\author{
Fabricio Ferreira de Oliveira', Benito Pereira Damasceno²
}

\begin{abstract}
Objective: To establish whether vascular aphasic syndromes can predict stroke outcomes. Method: Thirty-seven adults were evaluated for speech and language within 72 hours after a single first-ever ischemic brain lesion, in blind association to CT and/or MR. Results: Speech or language disabilities were found in seven (87.5\%) of the eight deceased patients and twenty-six (89.7\%) of the twenty-nine survivors. Global aphasia was identified in eleven patients, all with left hemisphere lesions (nine mute; five deceased), consisting on a risk factor for death in the acute stroke phase $(\rho=0.022)$. Age $(z=1.65 ; \rho>0.09)$, thrombolysis $(\rho=0.591)$, infarct size $(\rho=0.076)$ and side $(\rho=0.649)$ did not significantly influence survival. Absence of aphasia did not predict a better evolution, regardless of the affected hemisphere. Prevalence of cardiovascular risk factors was similar for all patient groups. Conclusion: Global aphasia in acute stroke can adversely affect prognosis, translated into impairment of dominant perisylvian vascular territories, with mutism as an important semiological element.
\end{abstract}

Key words: linguistics, aphasia, stroke, brain infarction, language, speech, disability evaluation, prognosis.

Afasia global prediz mortalidade na fase aguda de um primeiro acidente vascular cerebral isquêmico

\section{RESUMO}

Objetivo: Determinar se síndromes afásicas na fase aguda do infarto cerebral influenciam o prognóstico. Método: Avaliação para fala e linguagem de 37 adultos dentro de 72 horas após um primeiro infarto cerebral, em associação topográfica cega com TC e/ou RM. Resultados: Detectaram-se afasias ou disartria em 7 (87,5\%) dos 8 pacientes falecidos, e em $26(89,7 \%)$ dos 29 sobreviventes. Afasia global foi identificada em 11 pacientes, todos com lesões no hemisfério esquerdo (cinco óbitos; mutismo em nove), consistindo em fator de risco para mortalidade na fase aguda do acidente vascular cerebral isquêmico $(\rho=0,022)$. Idade $(z=1,65 ; \rho>0,09)$, trombólise $(\rho=0,591)$, dimensões da lesão $(\rho=0,076)$ e lado $(\rho=0,649)$ não afetaram significativamente a sobrevivência. Ausência de afasia não prenunciou melhor evolução. Fatores de risco cardiovascular tiveram similar prevalência

\section{Correspondence}

Fabricio Ferreira de Oliveira Departamento de Neurologia Faculdade de Ciências Médicas UNICAMP - Caixa Postal 6111 13083-970 Campinas SP - Brasil E-mail: fabricioferreiradeoliveira@ hotmail.com

\section{Support}

This study was supported by CAPES (Coordenação de Aperfeiçoamento de Pessoal de Nível Superior) - Brazil

Received 17 July 2010

Received in final form 20 November 2010

Accepted 29 November 2010 para todos os grupos de pacientes. Conclusão: Afasia global na fase aguda do infarto cerebral pode aumentar mortalidade, demonstrando envolvimento de território vascular perisylviano dominante, tomando-se mutismo como importante elemento semiológico. Palavras-chave: linguística, afasia, acidente cerebral vascular, infarto encefálico, linguagem, fala, avaliação da deficiência, prognóstico.

Aphasia may be identified in up to $40 \%$ of acute stroke patients ${ }^{1-5}$, but this percentage could be even higher, for the functional impairment in the key lin- guistic fields might be considered too mild to convey the notion that a language disturbance exists. Complicating factors for speech and language evaluation in acute 
stroke are, for instance, patient cooperation, the required length of time for a complete assessment, and stage of evolution of the brain injury.

Stroke is the leading cause of aphasia, which increases acute and chronic mortality rates after the cerebrovascular event ${ }^{5}$. Nonetheless, most studies that correlate stroke outcomes with aphasia evaluate recovery, not mortality. Rehabilitation strategies require good prognostic estimates not only of functional performance but also of morbidity and mortality. We sought to determine if outcomes for stroke patients can be influenced by recognition of a specific vascular aphasic syndrome in the acute phase of the brain injury, which would be topographically translated by the involvement of a defined vascular territory.

\section{METHOD}

This is a prospective and non-randomized study conducted at the Hospital das Clínicas -UNICAMP for a period of 12 months (May 2007 to April 2008), with the enrolment of all consecutive patients admitted to the Emergency Unit who developed a single first-ever ischemic stroke and fulfilled the established inclusion criteria: subjects had to be over 18 years-old, at any educational level, not comatose, with no evidences of previous strokes, and no history of previous brain diseases, decompensated systemic diseases, chronic alcohol ingestion or neurotoxic substance abuse; in addition, patients should have arrived within 72 hours after the acute stroke.

A neurologist with expertise on the assessment items (F.F.O.) would conduct the neurological evaluation no more than 72 hours after the stroke. The crucial aspects of the language testing were recorded in color with a digital camera. In case of uncertainties regarding the inquiry, the authors (F.F.O. and B.P.D.) would agree on a consensus when reviewing the evaluation.

A decision was made to comply the examination with the following directives ${ }^{6}$ :

[1] A brief history of the acute symptoms had to be reported by the patient (whenever possible) or a relative, including data on cardiovascular risk factors and socialeducational information, along with a complete neurological exam and a succinct assessment for hearing impairment (listening to finger-scratching with closed eyes, in each ear at once) and visual acuity;

[2] Patients were then tested for attentional deficits by means of the "A" Random Letter Test", being required to tap the unimpaired hand on the desk immediately after hearing the letter " $\mathrm{A}$ " (75 letters were orally presented by the examiner, 20 of them were "A" letters);

[3] Handedness was assessed according to a fivepoint scale of the Edinburgh Inventory ${ }^{8}$ for performance in writing, tooth-brushing, catching food with a spoon, opening a box, drawing, using a knife without fork, sweeping the floor (upper hand on the broomstick), throwing a ball, holding scissors, and striking a match;

[4] Visual perception was tested by showing the patients ten abstract figures in several levels of difficulty, each of them displayed for ten seconds, soon after which they would have to point to it among four other figures (scored as hit-or-miss) ${ }^{9}$;

[5] Phonemic perception was tested through repetition of 11 letters or phonemes: O, A, M, P, B, D, T, L, N, $\mathrm{G}\left(\right.$ guê), $\mathrm{Q}^{10}$;

[6] Evaluation of language and speech functions comprised: (A) Spontaneous narrative speech in answer to the inquiries "How are you?", “Tell me about your work!", "Tell me about your everyday activities!", recording the presence of mutism, poorness of speech, latency for response, coherence of response, comprehension impairment, phonemic or semantic paraphasias, neologisms, perseveration or echolalia, and grammatical errors (aggramatism); (B) Evaluation of fluency, considering the effort to respond, latency of response, phono-articulatory difficulties, phonetic mistakes and word-finding difficulty; (C) Study of comprehension with three yesor-no questions ("Is this place your home?", "Is the ant bigger than the elephant?", "Is your father's brother your uncle?") and three commands ("Show me your tongue!", "Raise your arms!", "Put your hand on my nose!"); (D) Repetition of four words ("casa", "banana", "floresta", "metalúrgico") and three sentences ("Hoje não está chovendo", "A lua brilha no céu", "De grão em grão a galinha enche o papo"), hereby transcribed in untranslated Portuguese; (E) Naming six simple objects (button, coin, clock, pen, match, nail); (F) Study of automatic speech by counting from 1 to 20, mentioning the seven days of the week, and fully singing the "Happy birthday..." song; (G) Evaluation of ideomotor praxis (putting the tongue between the upper lip and the upper teeth, whistling, waving goodbye, pretending to light and put out the fire of a match) and constructional praxis (copying two match-made figures, one of them with four matches resembling a triangle with an adjacent line, and the other with nine matches resembling two united pentagons).

Criteria for classification of vascular aphasic syndromes have been previously described ${ }^{11}$.

The inquiry for cardiovascular risk factors involved the following conditions: hypertension, diabetes mellitus, dyslipidemias, cigarette smoking, cardiac disorders (past myocardial infarction, angina pectoris, congestive heart failure with or without valvular heart disease, atrial fibrillation and other arrhythmias), alcoholism and illicit drug use. In case of alcoholics or illicit drug users, inclusion in the study would not be possible. Diagnosis of cardiac disorders had to be confirmed by other exams, such 
as an electrocardiogram or an echocardiogram. Blood pressure, fasting plasma glucose and cholesterol levels were monitored for all inpatients and outpatients. Definitions of risk factors such as hypertension ${ }^{12}$, diabetes mellitus $^{13}$ and dyslipidemias ${ }^{14}$ have been formerly published elsewhere.

Cerebral computed tomography (CT) and/or 2.0 Tesla magnetic resonance (MR) exams were solicited for topographic link between speech and language assessment results and the brain lesion site, both in the acute and the chronic phases (surviving patients would be submitted to MR or a new CT at an average of three months post-stroke). Preference was given to the MR, except in cases of patients who were claustrophobic or had metallic devices in their bodies; in such situations a $\mathrm{CT}$ had to be repeated in the chronic phase. All radiological exams were evaluated by two neurologists and by at least one radiologist. Subjects would be excluded from the study in case more than one defined brain lesion happened to be found, or if the stroke was restricted to areas of the central nervous system other than the brain itself. The examiner (F.F.O.) was blind to the topography of the brain damage during the query.

Radiological diagnosis was also employed to assess lesion size and side as possible predictors of mortality. Size of infarct was classified as large (more than $1.5 \mathrm{~cm}$ in diameter on CT or MR at any plane) or small (less than 1.5 $\mathrm{cm}$ in diameter on $\mathrm{CT}$ or MR at all planes), in accordance with the criteria used in the TOAST (Trial of Org 10172 in Acute Stroke Treatment) ${ }^{15}$ classification for stroke etiological subtypes.

Death by any cause in the acute phase of a first stroke was the main outcome measure. A correlation would be made between the aphasic syndrome presented at stroke onset and the probability of mortality.
The cut-off point for survival was set at 42 days poststroke (six weeks). This time period was chosen because subjects who would not survive were still inpatients and died within the first six weeks after the acute event, therefore leading one to consider a connection between the stroke and the cause of death. All surviving subjects were followed as outpatients from hospital discharge and for a period of at least three months after the acute cerebrovascular injury.

The chi-square test was used to compare categorical variables, except in case of small expected frequencies, when Fisher's exact test was used for evaluation of the contingency tables. Student's t-test was employed for quantitative variables. The threshold of significance was set at $\rho<0.05$.

This work is part of the research project 730/2006, approved by the Ethics Committee of the Faculty of Medical Sciences, University of Campinas - UNICAMP (CAAE 2081.0.000.146-06) on March 2007. All patients or their representatives signed the Informed Consent Form before the evaluation (we secured the assent of the next-of-kin if the patient were not able to write or comprehend). All the approached subjects agreed to participate.

\section{RESULTS}

A total of 37 adult subjects were enrolled in this study. Overall, acute phase speech or language disabilities (Table 1 ) occurred in seven $(87.5 \%)$ of the eight deceased patients and twenty-six (89.7\%) of the twentynine survivors. Twenty-nine patients (78.4\%) survived for more than 42 days after the stroke (Table 2): three without aphasia or dysarthria at admission (two with left hemisphere lesions and one with a right lesion), twelve with lone cortical dysarthria (five with left lesions and

Table 1. General characteristics of studied patients.

\begin{tabular}{lc}
\hline Analyzed characteristics & Acute stroke \\
\hline $\mathrm{n}$ & 37 \\
Male gender (\%) & $22(59.4 \%)$ \\
Female gender (\%) & $15(40.6 \%)$ \\
Mean age in years \pm SD; (SEM) & $63.96 \pm 11.30 ;(1.86)$ \\
Mean years of schooling \pm SD; (SEM) & $4.78 \pm 4.13 ;(0.68)$ \\
Overall presence of speech or language disabilities & $33(89.2 \%)$ \\
$\quad$ Left hemisphere strokes in the aphasic/dysarthric patients & $25(75.8 \%)$ \\
$\quad$ Right hemisphere strokes in the aphasic/dysarthric patients & $8(24.2 \%)$ \\
Overall survival for more than 6 weeks after the stroke & $29(78.4 \%)$ \\
$\quad$ Presence of aphasia in the first 72 hours post-stroke for patients who survived over 42 days & $14(48.3 \%)$ \\
$\quad$ Presence of dysarthria in the first 72 hours post-stroke for patients who survived over 42 days & $12(41.4 \%)$ \\
$\quad$ Survivors without speech or language disabilities & $3(10.3 \%)$ \\
\hline
\end{tabular}

SD: standard deviation; SEM: standard error of the mean. 
Table 2. Distribution of subtypes of speech and language disturbances according to the assessment in the first 72 hours after the acute stroke.

\begin{tabular}{lccc}
\hline Type of disturbance & $\mathbf{n}(\%)$ & $\begin{array}{c}\text { Survivors (after the first } \\
\text { 6 weeks post-stroke) }\end{array}$ & $\%$ Survival \\
\hline Lone cortical dysarthria & $13(35.2 \%)$ & 12 & $92.3 \%$ \\
Global aphasia & $11(29.7 \%)$ & 6 & $54.5 \%$ \\
Broca's aphasia & $3(8.1 \%)$ & 3 & $100 \%$ \\
Wernicke's aphasia & $2(5.4 \%)$ & 2 & $100 \%$ \\
Mixed transcortical aphasia & $2(5.4 \%)$ & 1 & $50.0 \%$ \\
Transcortical motor aphasia & $1(2.7 \%)$ & 1 & $100 \%$ \\
Thalamic aphasia & $1(2.7 \%)$ & 1 & $100 \%$ \\
No aphasia or dysarthria & $4(10.8 \%)$ & 3 & $75.0 \%$ \\
Total & 37 & 29 & $78.4 \%$ \\
\hline
\end{tabular}

Table 3. Prevalence of selected cardiovascular risk factors according to outcome in terms of survival.

\begin{tabular}{|c|c|c|c|c|c|}
\hline \multirow{2}{*}{$\begin{array}{l}\text { Cardiovascular } \\
\text { risk factor* }\end{array}$} & \multicolumn{2}{|c|}{ Global aphasia patients } & \multicolumn{2}{|c|}{ Other patients } & \multirow[b]{2}{*}{$\rho$ value $^{\dagger}$} \\
\hline & Survivors $(n=6)$ & Deceased $(n=5)$ & Survivors ( $n=23$ ) & Deceased $(n=3)$ & \\
\hline Hypertension & $4(66.7 \%)$ & $4(80.0 \%)$ & $21(91.3 \%)$ & $2(66.7 \%)$ & 0.591 \\
\hline Diabetes mellitus & $3(50.0 \%)$ & $2(40.0 \%)$ & $11(47.8 \%)$ & $1(33.3 \%)$ & 0.701 \\
\hline Dyslipidemia & $3(50.0 \%)$ & 0 & $10(43.5 \%)$ & $1(33.3 \%)$ & 0.123 \\
\hline Atrial fibrillation & $2(33.3 \%)$ & $3(60.0 \%)$ & $4(17.4 \%)$ & 0 & 0.373 \\
\hline CAD/heart failure & $1(16.7 \%)$ & $2(40.0 \%)$ & $8(34.8 \%)$ & $1(33.3 \%)$ & 0.999 \\
\hline Smoker ${ }^{\ddagger}$ & $3(50.0 \%)$ & $2(40.0 \%)$ & $12(52.2 \%)$ & $3(100 \%)$ & 0.701 \\
\hline
\end{tabular}

*Patients who were alcoholics or illicit drug users were not included in the study; ${ }^{\dagger}$ The $\rho$ value is estimated according to Fisher's exact test; ${ }^{\ddagger}$ Former smoker for a period of at least ten years, or current regular smoker at stroke onset. Other patients: patients who did not show signs of global aphasia in the acute stroke phase; CAD: coronary artery disease.

seven with right lesions), six with global aphasia (all with left lesions), three with Broca's aphasia (all with left lesions), two with Wernicke's aphasia (both with left lesions), one with a left lesion and signs of thalamic aphasia, one with mixed transcortical aphasia (left injury) and one with transcortical motor aphasia (also a left injury). Apraxia of speech was not identified in any of the subjects. Among the eight patients who did not survive for more than 42 days after the stroke, three developed brain herniation and died within two to four days (two of them had a global aphasia in the acute phase), one developed an aortic dissection and died within six days (in the post-operative period), two died in the second week, one died during the fifth week, and one died at the end of the sixth week after the acute brain lesion; all of them were still inpatients at the time of death.

Mean age was 69.272 years-old for the eight deceased patients (range 57.359-85.890 years-old, $\mathrm{s}=12.091$ years, $\mathrm{SEM}=4.275$, coefficient of variation $17.454 \%$ ) and 62.123 years-old for the twenty-nine survivors (range 39.34280.230 years-old, $s=11.034$ years, $S E M=2.049$, coefficient of variation $17.762 \%$ ), but it had no significant impact on survival $(z=1.65 ; \rho>0.09)$. Prevalence of cardiovascular risk factors was similar for both deceased and surviving groups of patients (Table 3); outcomes in terms of survival were not significantly affected by their presence.

Ranging scores from 10 to 50 in the Edinburgh Inventory ${ }^{8}$, two male patients (one with a score of 42 and a lone cortical dysarthria, and the other one with a score of 46 who did not show signs of aphasia or dysarthria) were considered left-handed. All other patients had scores between 10 and 18, and were considered right-handed.

Global aphasia was identified in 11 patients: all of them had left hemisphere lesions; five of them died within 42 days after the stroke, and six survived later on; nine of them were mute. Hence, it was statistically demonstrated that global aphasia consisted on a risk factor for death in the acute stroke phase $\left(\chi^{2}=5.238779\right.$; $\rho=0.022$ ). Absence of aphasia with or without dysarthria did not predict a better evolution, regardless of the affected hemisphere, but the study was not powered enough for the analysis of these data because of the small number of non-aphasics in the sample.

Seventeen patients (45.95\%) were submitted to cerebral MR either in the acute or the chronic stroke phase; because of their poor medical status as inpatients, none 
of the eight deceased patients could undertake such exam. A cerebral CT scan was performed no less than once for all thirty-seven patients in the acute phase. All patients had at least one cerebral scan which was considered informative enough for the study. On the whole, only two patients (5.4\%) did not show a classic lesion site corresponding to the speech and language assessment results: one with Wernicke's aphasia who had a right frontal cortical lesion, and one with no speech or language disorder who had a right hemisphere lesion corresponding to the full middle cerebral artery territory (at least a mild dysarthria would be expected in this case); both of them were male, supposedly right-handed, and could not undertake the MR exam.

All patients with global aphasia $(n=11)$ had large infarcts in the left hemisphere. All deceased patients $(n=8)$ had large infarcts as well, but seven of them were injured in the left hemisphere and one in the right. Among the survivors without global aphasia $(\mathrm{n}=23)$, twelve had large infarcts and eleven had small ones; amid these survivors, fifteen had left hemisphere lesions, and eight had them on the right. However, lesion size $(\rho=0.076)$ and side $(\rho=0.649)$ were not predictive of survival on this sample.

Among the 37 subjects, a total of six patients fulfilled the established criteria for thrombolysis and received rtPa in the acute stroke phase: three of them had global aphasia, one had isolated cortical dysarthria, one had Broca's aphasia and one had mixed transcortical aphasia. Two of the three patients with global aphasia who were thrombolysed eventually died (one of them died two days after the stroke, and the other one died after eleven days); four of the six thrombolysed patients survived for more than six weeks post-stroke. However, thrombolytic treatment did not significantly influence survival on this sample $(\rho=0.591)$.

\section{DISCUSSION}

Short-term mortality was higher for patients with aphasia in this sample, more often so when global aphasia was present, in accordance with other authors ${ }^{5}$. Some studies have revealed that long-term mortality is correlated with the occurrence of aphasia as well ${ }^{1,5}$. Global aphasia has also been shown to bring an unfavorable prognosis to post-stroke mobility recovery ${ }^{16}$; this could be phylogenetically related to the simultaneous development of language networks and motor gesture activity in earlier primates ${ }^{17}$. On the other hand, former studies have shown that the nondominant hemisphere for language has a critical role in the recovery of aphasia, probably related to the lexical learning itself present in healthy subjects and to mechanisms of brain plasticity ${ }^{3,11,18,19}$; recruitment of networks in the nondominant hemisphere is believed to occur concurrently with attempts to repair the damaged original language networks in aphasic patients ${ }^{3,11,18}$.

Quality-of-life scales for stroke patients often include aphasia as a measure of neurological compromise in the long term ${ }^{20}$. This is important if we take into consideration that even patients who go on without visual or motor deficits can be severely impaired for their regular activities if aphasia is present, and the length of their hospital stays is usually longer ${ }^{21-23}$. In regard to the short term, the National Institutes of Health Stroke Scale $(\mathrm{NIHSS})^{24}$, the most widely used scale for thrombolysis evaluation, may display a loss of up to eight points if the patient has global aphasia: two points for level of consciousness questions, two points for level of consciousness commands, one point for sensory loss, and three points for best language. Considering that global aphasia, the most severe aphasic syndrome, is typically the result of large lesions in the middle cerebral artery territory of the dominant hemisphere for language ${ }^{4}$, patients usually lose points for motor items and for dysarthria as well, leading to a probable high score. These facts could partly explain some of the prognostic results we found.

None of our patients met the established criteria for conduction aphasia, anomic aphasia, non-thalamic subcortical aphasia or apraxia of speech. This could be due to our sample size, but also to the strictness of our inclusion criteria leading only to acute stroke patients being recruited for the study. Furthermore, the proportion of patients with aphasia in the acute phase was higher than expected; this finding could be explained by the fact that only subjects with brain lesions were included (and not patients with cerebellar or brainstem ischemic lesions), and also because our university hospital is a reference for stroke patients, with a tendency for admitting more severe cases with larger stroke sizes.

Classic clinical-anatomic correlations ${ }^{2,25}$ were met pertaining stroke topography in relation to the aphasic syndrome presented in almost $95 \%$ of studied subjects. The two patients who did not correspond to the expected brain lesion site could have some individual variation in the cytoarchitecture of language networks and, with specific regard to the patient with Wernicke's aphasia, the language disturbance could be attributed to a temporary hypoperfusion of the left temporal cortex in the acute phase, or to a case of crossed aphasia with predominant impairment in comprehension due to dysfunctional neural tissue surrounding the original lesion.

Even though some acute stroke patients did not promptly cooperate, they were still tested one or two days later, respecting the 72-hour post-stroke time. Considering that comatose patients were not included, 100\% of the approached subjects were tested in the end. We also avoided functional communication assessments in 
our evaluation because they are less reliable for acute stroke patients ${ }^{20}$.

The severity of vascular aphasic syndromes is usually associated with stroke severity ${ }^{5}$. Controversial results in regard to evaluation of aphasia may be obtained in the presence of confusion factors like the catastrophic reaction $^{26}$ and post-stroke depression ${ }^{27}$, which are more frequent in aphasic patients (probably as a reactional mechanism). The only feature that is knowingly associated to the severity of depressive symptoms is the volume of the brain lesion ${ }^{28}$. In our sample, all patients with depression were assessed and treated, and no cases of catastrophic reaction were encountered.

Rehabilitation strategies are less successful for global aphasia patients, resulting in reduced post-stroke functional recovery ${ }^{29}$. By and large, aphasia can be an important component of the syndrome named "vascular cognitive impairment"21; therefore, language impairment after stroke is usually related to a lesser probability of independence on activities of daily living, and also on the chances of returning to work or previous social activities.

Prognosis for speech and language in acute stroke is hard to quantify ${ }^{4,6,30}$. Patients with nonfluent aphasias may evolve to fluent forms ${ }^{5,6}$, but when global aphasia is present in the acute stroke phase and does not completely resolve, a predominant loss of fluency is often observed $^{6}$. Interobserver agreement is usually lower among patients assessed very early and very late after symptom onset. Published data are available to support the fact that increasing experience and specific training may lead to a more accurate diagnosis in time ${ }^{31}$. Since most studies tend to evaluate vascular aphasia in the chronic phase, more data is needed for acute stroke patients with speech and language disturbances.

The major weakness of this study was its small sample size, which led to limitations in regard to the amplitude of correlations between aphasic syndromes and the topography of the brain lesions. In view of the fact that global aphasia was the most common form of language disorder in the acute stroke phase, it was the only one to which we could establish a defined prognostic value. Studies with larger samples are required to evaluate if other forms of aphasia can also have some power in the forecasting of outcomes.

In conclusion, global aphasia in acute stroke can adversely affect prognosis for patient survival, possibly because it denotes involvement of perisylvian vascular territories in the dominant hemisphere for language (large middle cerebral artery territories). Mutism is an important semiological component for this diagnosis.

ACKNOWLEDGMENTS - We are indebted to our patients and their families for kindly agreeing to participate on the study.

\section{REFERENCES}

1. Bakheit AMO, Shaw S, Carrington S, Griffiths S. The rate and extent of improvement with therapy from the different types of aphasia in the first year after stroke. Clin Rehabil 2007;21:941-949.

2. Breier JI, Hasan KM, Zhang W, Men D, Papanicolaou AC. Language dysfunction after stroke and damage to white matter tracts evaluated using diffusion tensor imaging. Am J Neuroradiol 2008;29:483-487.

3. Dobkin BH. Rehabilitation after stroke. N Engl J Med 2005:352:1677-1684.

4. Inatomi Y, Yonehara T, Omiya S, Hashimoto Y, Hirano T, Uchino M. Aphasia during the acute phase in ischemic stroke. Cerebrovasc Dis 2008;25:316-323.

5. Laska AC, Hellblom A, Murray V, Kahan T, von Arbin M. Aphasia in acute stroke and relation to outcome. J Intern Med 2001:249:413-422.

6. Oliveira FF, Damasceno BP. Short-term prognosis for speech and language in first stroke patients. Arq Neuropsiquiatr 2009;67:849-855.

7. Strub RL, Black FW. The mental status examination in neurology. $4^{\text {th }}$ edition. Philadelphia: Davis, 2000.

8. Oldfield RC. The assessment and analysis of handedness. The Edinburgh Inventory. Neuropsychologia 1971;9:97-113.

9. Jones-Gotman M, Zatorre RJ, Olivier A, et al. Learning and retention of words and designs following excision from medial or lateral temporallobe structures. Neuropsychologia 1997;35:963-973.

10. Christensen AL. Luria's Neuropsychological Investigation. $2^{\text {nd }}$ edition. Copenhagen: Munksgaard, 1979.

11. Hillis AE. Aphasia: Progress in the last quarter of a century. Neurology 2007; 69:200-213.

12. Chobanian AV, Bakris GL, Black HR, et al. The Seventh Report of the Joint National Committee on prevention, detection, evaluation and treatment of high blood pressure: the JNC 7 Report. JAMA 2003;289:2560-2572.

13. American Diabetes Association. Diagnosis and classification of diabetes mellitus. Diabetes Care 2006;29(Suppl 1):S43-S48.

14. National Cholesterol Education Program. Third Report of the National Cholesterol Education Program (NCEP) Expert Panel on detection, evaluation, and treatment of high blood cholesterol in adults (Adult Treatment Panel III) Final Report. Circulation 2002;106:3143-3421.

15. Adams HP, Bendixen BH, Kappelle $L$ J, et al. Classification of subtype of acute ischemic stroke: definitions for use in a multicenter clinical trial. Stroke 1993;24:35-41.

16. Paolucci S, Bragoni M, Coiro P, et al. Quantification of the probability of reaching mobility independence at discharge from a rehabilitation hospital in nonwalking early ischemic stroke patients: a multivariate study. Cerebrovasc Dis 2008;26:16-22.

17. Meister IG, Sparing R, Foltys $H$, et al. Functional connectivity between cortical hand motor and language areas during recovery from aphasia. J Neurol Sci 2006;247:165-168.

18. Fernandez B, Cardebat D, Demonet JF, et al. Functional MRI follow-up study of language processes in healthy subjects and during recovery in a case of aphasia. Stroke 2004;35:2171-2176.

19. Raboyeau G, De Boissezon X, Marie N, et al. Right hemisphere activation in recovery from aphasia: Lesion effect or function recruitment? Neurology 2008;70:290-298.

20. Laska AC, Bartfai A, Hellblom A, Murray V, Kahan T. Clinical and prognostic properties of standardized and functional aphasia assessments. J Rehabil Med 2007:39:387-392

21. Lesniak M, Bak T, Czepiel W, Seniów J, Czlonkowska A. Frequency and prognostic value of cognitive disorders in stroke patients. Dement Geriatr Cogn Disord 2008;26:356-363.

22. Panicker JN, Thomas M, Pavithran K, Nair D, Sarma PS. Morbidity predictors in ischemic stroke. Neurol India 2003;51:49-51.

23. Wee JYM, Hopman WM. Stroke impairment predictors of discharge function, length of stay, and discharge destination in stroke rehabilitation. Am J Phys Med Rehabil 2005;84:604-612.

24. Brott T, Adams HP Jr, Olinger CP, et al. Measurements of acute cerebral infarction: a clinical examination scale. Stroke 1989;20:864-870.

25. Kreisler A, Godefroy O, Delmaire C, et al. The anatomy of aphasia revisited. Neurology 2000;54:1117-1123.

26. Carota A, Rossetti AO, Karapanayiotides T, Bogousslavsky J. Catastrophic reaction in acute stroke: a reflex behavior in aphasic patients. Neurology 2001;57:1902-1905.

27. Toso V, Gandolfo C, Paolucci S, Provinciali L, Torta R, Grassivaro N. Poststroke depression: research methodology of a large multicentre observational study (DESTRO). Neurol Sci 2004;25:138-144.

28. Nys GMS, Van Zandvoort MJE, Van der Worp HB, De Haan EHF, De Kort PLM, Kappelle LJ. Early depressive symptoms after stroke: neuropsychological correlates and lesion characteristics. J Neurol Sci 2005;228:27-33.

29. Zinn S, Bosworth HB, Hoenig HM, Swartzwelder HS. Executive function deficits in acute stroke. Arch Phys Med Rehabil 2007:88:173-180.

30. Lazar RM, Speizer AE, Festa JR, Krakauer JW, Marshall RS. Variability in language recovery after first-time stroke. J Neurol Neurosurg Psychiatry 2008; 79:530-534.

31. Hand PJ, Haisma JA, Kwan J, et al. Interobserver agreement for the bedside clinical assessment of suspected stroke. Stroke 2006;37:776-780. 